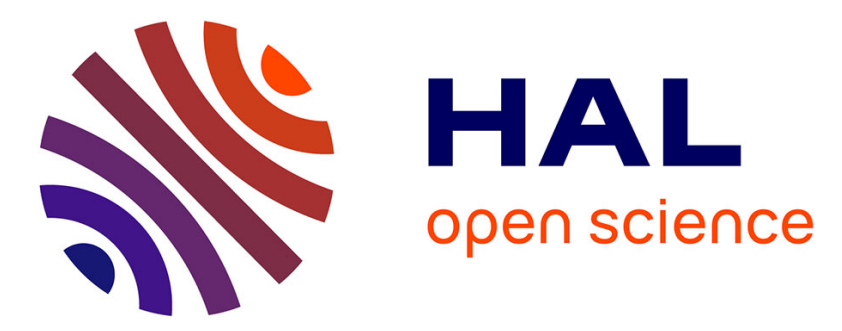

\title{
Development and validation of an electrical and magnetic characterization device for massive parallelepiped specimens
}

Meryeme Toto Jamil, Abdelkader Benabou, Stéphane Clénet, Laure Arbenz, Jean-Claude Mipo

\section{To cite this version:}

Meryeme Toto Jamil, Abdelkader Benabou, Stéphane Clénet, Laure Arbenz, Jean-Claude Mipo. Development and validation of an electrical and magnetic characterization device for massive parallelepiped specimens. International Journal of Applied Electromagnetics and Mechanics, 2019, 61 (supplément 1), pp.S31-S38. 10.3233/jae-191491 . hal-03194578

\section{HAL Id: hal-03194578 \\ https://hal.science/hal-03194578}

Submitted on 9 Apr 2021

HAL is a multi-disciplinary open access archive for the deposit and dissemination of scientific research documents, whether they are published or not. The documents may come from teaching and research institutions in France or abroad, or from public or private research centers.
L'archive ouverte pluridisciplinaire HAL, est destinée au dépôt et à la diffusion de documents scientifiques de niveau recherche, publiés ou non, émanant des établissements d'enseignement et de recherche français ou étrangers, des laboratoires publics ou privés. 


\title{
Development and validation of an electrical and magnetic characterization device for massive parallelepiped specimen
}

${ }^{1,2}$ Meryeme Jamil, ${ }^{1}$ Abdelkarder Benabou, ${ }^{1}$ Stéphane Clénet, ${ }^{2}$ Laure Arbenz, ${ }^{2}$ Jean-Claude Mipo

${ }^{1}$ Univ. Lille, Arts et Metiers ParisTech, Centrale Lille, HEI, EA 2697 - L2EP -Laboratoire d'Electrotechnique et d'Electronique de Puissance, 59655 Villeneuve d'Ascq, France ${ }^{2}$ Valeo Powertrain Systems, 2 Rue André Charles Boulle, 94046 Créteil Cedex, France Coresponding author : ${ }^{1}$ Abdelkarder Benabou

E-mail: Abdelkader.Benabou@univ-lille.fr, Tel: ++33 32043 46 96, (Fax: ++33 3204369 67)

\begin{abstract}
Claw pole machine performances are strongly related to the electromagnetic properties of ferromagnetic materials. These properties are impacted by the manufacturing processes, in a heterogeneous way, as well as by the thermal behavior of the machine and the mechanical stress distribution. Due to the complexity of CP geometry, extracted samples cannot respect the dimensions prescribed in international standards of electric and magnetic measurements. This paper proposes a specific methodology to characterize the electrical conductivity and the magnetic behavior of massive parallelepiped specimens extracted from different locations of a CP rotor.
\end{abstract}

Keywords: Claw pole rotor, electromagnetic properties, mini SST, four point measurement, correction factor, FE simulation. 


\section{Introduction}

The Claw Pole (CP) alternator is a three-phase electrically magnetized synchronous machine, widely used in the automotive sector for the electromechanical energy conversion. To improve its efficiency and its performances, it is important to know as much as possible each part of the machine. This challenging task is the key to understand, more deeply, the machine operating mode, in order to be able to model, to simulate and to optimize it. In particular, the CP rotor is one of the critical components of the CP machine. Its role is to channel the magnetic flux, created by an excitation coil, from the rotor to the stator with a limited leakage flux. Its operating efficiency is directly related to the electromagnetic properties of the $\mathrm{CP}$ material. This latter is made of a soft ferromagnetic material with a moderated electrical conductivity in order to reduce the eddy current losses. Due to the magnetic core complex geometry, standard characterization techniques are inappropriate to measure its electromagnetic properties. In this study, we propose a specific methodology to characterize the $\mathrm{CP}$ electrical conductivity and magnetic properties through the development of a four probes method and a miniaturized Single Sheet Tester (mini-SST).

\section{Case study}

Unlike other magnetic core types, the $\mathrm{CP}$ has a particular geometry that requires a specific study. It is a massive heterogeneous core in terms of magnetic properties, with a complex geometry and through which the flux flows in 3D. In Figure 1, the main flux path through the magnetic circuit is illustrated.

Figure 1: Main Magnetic flux path through 1/6th of the CP

In the specific case of the $\mathrm{CP}$ rotor, the electromagnetic properties are significantly impacted by the manufacturing process, and by the operating conditions, in a heterogeneous way regarding the volume properties. On the one hand, the electric and magnetic characteristics of the machine components are different from those of the raw material [1]. On the other hand, the electromagnetic properties vary not only in a given $\mathrm{CP}$ but also from one to another [2]. Extensive researches on the interactions between processes, electromagnetic properties and other material properties have been done in the case of the laminated sheet steel [3], but rarely in the case of massive forged steel [2]. Moreover, samples extracted 
from the $\mathrm{CP}$ cannot respect the dimensions prescribed in international measurement standards. In this work, the magnetic flux path, the $\mathrm{CP}$ heterogeneity and the claw shape made it necessary to use parallelepiped samples extracted, according to the flux path, from different locations of the CP.

\section{Experimental setup}

3.1. The four-point method

Figure 2 Four point method

The electrical conductivity measurement is based on the four-point method [4]. The four needles are arranged on a straight line with $6 \mathrm{~mm}$ equidistant spacing, the current is imposed flowing through the outer pair of needles and the voltage is measured between the two inner needles (Figure 2). Because of the inhomogeneous current flux path between the outer needles which depends on the shape of the sample, the calculation of the electrical conductivity is not straightforward and a geometrical correction factor F must be introduced to the conductivity formula. Thus, the electrical DC conductivity reads:

$$
\sigma=\frac{I \ell}{V S} F,
$$

where $\sigma$ is the electrical conductivity, I current, $\ell$ the distance between the voltage probes, $\mathrm{V}$ the measured voltage, $\mathrm{S}$ the section of the sample and $\mathrm{F}$ is the correction factor. The measurement uncertainty of the method used has been evaluated and minimized using the 5M method [5].

\subsection{The correction factor}

The correction factor $\mathrm{F}$ can be calculated analytically for specific geometries of samples and positioning of the point probes regarding the sample edges. Different methods are then proposed [6], such as the method of images [7], complex variable theory, the method of Corbino sources, Poisson's equation [8], Green's functions and conformal mapping. Yet, in our case, the geometrical hypotheses are not fulfilled as the sample dimensions are relatively small regarding its thickness. Therefore, we propose to determine the sample correction factor from numerical simulations using $3 \mathrm{D}$ electrokinetic field calculation. 
The model is based on the solution of the electrokinetic problem solved by the finite element method using the scalar potential formulation. The electrical conductivity is defined as input parameter as well as the current I flowing through the external needles of the sensor. The resulting voltage $\mathrm{V}$ between the internal needles is obtained from the numerical simulation. Finally, the correction factor F can be deduced from (1) for a given value of the conductivity.

In the particular case of very thin sample $(\mathrm{t}<\ell / 2)$, analytical [6] and numerical simulation calculations give the same correction factor, which validate our numerical approach.

Calculated correction factors $\mathrm{F}$ are reported in Figure 3. This correction factor $\mathrm{F}$ of the electrical conductivity depends on the sample dimensions. It increases with the increase of the sample width (w) and thickness ( $\mathrm{t}$ ) and it decreases when the sample length increases.

Figure 3: Abacus of the geometrical correction factor numericaly calculated according to equation

(1) for different sample dimensions with a parallepipedic shape. (a) The correction factor vs the sample thickness for five different widths at fixed length $(\mathrm{L}=20 \mathrm{~mm})$. (b) The correction factor vs the sample width for three different lengths at fixed thichness $(\mathrm{t}=1 \mathrm{~mm})$

\subsection{The mini SST}

Magnetic properties are measured using a miniaturized single sheet tester (SST) as in [9]. Figure 4 illustrates the proposed miniaturized SST. The setup is composed of a laminated C-core (yoke), with a 75 turns primary coil wound on the inner face of the yoke to prescribe a field gradient between the two rectangular surfaces at the yoke extremities creating a North and a South poles [10]. The secondary coil is 47 turns wound around the sample in the region where the magnetic flux is homogeneous. The sample is then placed above the yoke between its two poles to close the magnetic path. The experiments were carried out on a bulk sample with dimensions $10 \mathrm{~mm}$ (width) $* 35 \mathrm{~mm}$ (length)* $1 \mathrm{~mm}$ (thickness). The distance between the inner sides of the yoke poles is $13 \mathrm{~mm}$.

Figure 4: Photography (a) and schematic view (b) of the mini SST

The magnetic field determination is based on the fact that across the interface between two different materials (such as between air and ferromagnetic material) the tangential component of the magnetic 
field, $\mathrm{H}_{\mathrm{t}}$, is continuous: $\mathrm{H}_{\mathrm{t}, \mathrm{arr}}=\mathrm{H}_{\mathrm{t}, \text { mat. }}$. For low frequencies (which is the case in this study), the effective magnetic field inside the sample is quasi-uniform over the cross section of the sample (in other words no significant skin effect occurs). Therefore, the determined effective magnetic field at the surface of the sample is actually a measure of the magnetic field $\mathrm{H}$ inside the sample. Moreover, based on the consideration of homogeneous magnetic induction all along the secondary winding, the average magnetic flux density calculated from the secondary winding defines the magnetic flux density inside the sample. The induction is deduced from the voltage that is induced into the secondary winding:

$$
B(t)=\frac{1}{N_{2} S} \int v_{2} d t
$$

where B is the induction, $\mathrm{N} 2$ the number of turns of the secondary winding (for the investigated sample), $\mathrm{S}$ is the cross-section area of the tested sample, and $\mathrm{v} 2$ is the secondary voltage.

The magnetic field, generated by the primary circuits, in the sample is measured from two calibrated Hall effect sensors. The sensors are placed, as close as possible, above the specimen. In order to determine the tangential component of the magnetic field, i.e. the field at the sample surface, and so in the sample, the fields obtained from the sensors are used for a two-point linear extrapolation. This approach is justified by the observation that in a small region close to the sample surface, the magnetic field increases more or less in a linear way with distance from the sample surface, as it is illustrated by the numerical results in Figure 5.

Figure 5: Numerical results of the 3D FE simulation. Simulated distribution of the magnetic field $\mathrm{H}$ as a function of $\mathrm{y}$ axis at the sample center $(\mathrm{x}=0, \mathrm{z}=0$ ). From the sensor position (see inset (a)) $\mathrm{Y} 1=-6.5 \mathrm{~mm}$ and $\mathrm{Y} 2=-3.5 \mathrm{~mm}$, a linear extrapolation (shown graphically by the red line) towards the sample surface $y=-0.5 \mathrm{~mm}$ enables to determine the magnetic field at the surface of the sample

In order to design the experimental bench, to confirm the hypotheses and to validate the measurement method, numerical 2D / 3D simulations were performed. First, a 2-D FEM model was proposed. Then, a 3-D FEM model of the proposed SST was developed so that the 3D effects like 3D leakage flux or fringing effects could be considered. The numerical model is based on the solution of the magneto-static problem solved by the finite element method using the scalar potential formulation. The simulation 
results demonstrate that the effective magnetic field and the magnetic flux density inside the sample are quasi-homogeneous over the cross section of the sample, as shown in Figure 6.

Figure 6: Numerical results of the 3D FE simulation. (a) Magnetic induction B (T) and (b) Magnetic field H (A/m) distribution in the mini SST (yoke and sample)

\section{Results and discussion}

The results of the electrical conductivity characterization of 17 samples extracted from the same $\mathrm{CP}$ are presented in Figure 7. As expected, the electrical conductivity is homogeneous throughout the CP. This is explained by the fact that the conductivity depends highly on the chemical composition and not so much from the microstructure and the stress distribution which are strongly inhomogeneous in the CP [11].

Figure 7: Experimental measurement of the electrical conductivity in different locations of a CP using the proposed four point method based approach. The inset above illustrates the four different areas of sampling (A, B, C and D)

In addition to the numerical verification, experimental measurement was carried to verify the proposed method. A comparison of B-H curves obtained at $5 \mathrm{~Hz}$ on ring core measurement and mini SST is shown in Figure 8. First, it should be noted that the two sample types were extracted from two different CPs. The ring cores were cut by machining while the mini SST parallelepiped samples were cut by electrical discharge machining. Last, at the high induction region, the gap between the $\mathrm{B}(\mathrm{H})$ curves could be explained by the microstructural heterogeneity. In fact, even if the chemical composition is identical for all specimens, due to the hot forging process a more or less significant presence of the non-ferritic phase (cementite $\mathrm{Fe} 3 \mathrm{C}$ included in the pearlite) may be induced depending on the locations in the CP. So the distribution of the second phase may differ from one sample to another. In Figure 8, the B-H curves obtained by the proposed mini SST are in the range of variation of the one measured for four ring cores, extracted from different locations of the CP.

Figure 8: Comparison of $\mathrm{CP} B(\mathrm{H})$ curves measured with the mini SST and $\mathrm{CP} B(\mathrm{H})$ reference curves obtained from the ring core measurement at $5 \mathrm{~Hz}$. The inset illustrates the sampling areas. 
The measurement repeatability was investigated by repeating ten times the same measurement series according to the same protocol for the mini SST. For each magnetic field of the B-H curve, the calculated standard deviation $\sigma$ is no more than $5 \mathrm{mT}$, and all the measurements lie within $\pm 3 \sigma$ of the mean B-H curve. Therefore, the confidence level of the mini SST measurement is estimated at about $99.7 \%$. Thereafter, it could be interesting to carry out a full statistic study to determine the precision of the measurement (measurement reproducibility and repeatability).

\section{Conclusion}

In the case of $\mathrm{CP}$ rotor, standard characterization techniques are not able to evaluate the local electromagnetic properties of the material. We proposed a specific methodology to characterize the electrical conductivity and the magnetic behavior of small massive parallelepiped specimens extracted from different locations of a CP rotor. The electrical conductivity was characterized using the four points method with the application of a geometry correction factor numerically calculated. Then, a magnetic characterization "mini SST" device was designed and developed to measure the B-H curves. The assumed hypotheses of the proposed approach were verified using 3D Finite Element simulations. Moreover, the experimental measurements are consistent with the well-known ring core method. This methodology will be then used to study the electromagnetic properties of $\mathrm{CP}$ depending on the electrical machine operating temperatures. 


\section{References}

[1] L. Arbenz, A. Benabou, S. Clénet, J. Mipo, and P. Faverolle, "Characterization of the Local Incremental Permeability of a Ferromagnetic Plate Based on a Four Needles Technique," IEEE Trans. Magn., vol. 53, no. 3, pp. 1-7, Mar. 2017.

[2] M. Borsenberger, A. Benabou, C. Baudouin, R. Bigot, P. Faverolle, and J.-C. Mipo, "Characterization of massive magnetic parts with a dedicated device," Int J Appl Electrom, pp. 1$16,2018$.

[3] M. E. Youssef et al., "Slinky stator: The impact of manufacturing process on the magnetic properties," in 2017 IEEE International Electric Machines and Drives Conference (IEMDC), 2017, pp. 1-8.

[4] L. Arbenz, A. Benabou, S. Clenet, jean claude MIPO, and P. Faverolle, "Characterization of the local Electrical Properties of Electrical Machine Parts with non-Trivial Geometry," Int. J. Appl. Electromagn. Mech., vol. 48, no. 2\&3, pp. 201-206, Jun. 2015.

[5] K. Ishikawa, "Introduction to Quality Control” 1990.

[6] D. K. Schroder, Semiconductor Material and Device Characterization. John Wiley \& Sons, 2006.

[7] F. M. Smits, "Measurement of Sheet Resistivities with the Four-Point Probe," Bell Syst. Tech. J., vol. 37, no. 3, pp. 711-718, May 1958.

[8] M. Yamashita, "Resistivity Correction Factor for Four-Probe Method on Circular Semiconductors II,”Jpn. J. Appl. Phys., vol. 27, no. 7R, p. 1317, Jul. 1988.

[9] M. De Wulf, D. Makaveev, Y. Houbaert, and J. Melkebeek, "Design and calibration aspects of small size single sheet testers," J. Magn. Magn. Mater., vol. 254-255, pp. 70-72, Jan. 2003.

[10]O. Stupakov, I. Tomáš, and J. Kadlecová, “Optimization of single-yoke magnetic testing by surface fields measurement,” J. Phys. Appl. Phys., vol. 39, no. 2, pp. 248-254, Jan. 2006.

[11]G. Lyudkovsky, P. K. Rastogi, and M. Bala, "Nonoriented Electrical Steels," JOM, vol. 38, no. 1, pp. 18-26, Jan. 1986. 


\section{Figure captions}

Figure 1: Main Magnetic flux path through 1/6th of the CP.

Figure 2: Four point method

Figure 3: Abacus of the geometrical correction factor numericaly calculated according to equation (1) for different sample dimensions with a parallepipedic shape. (a) The correction factor vs the sample thickness for five different widths at fixed length $(\mathrm{L}=20 \mathrm{~mm})$. (b) The correction factor vs the sample width for three different lengths at fixed thichness $(\mathrm{t}=1 \mathrm{~mm})$ 12

Figure 4: Photography (a) and schematic view (b) of the mini SST. 14

Figure 5: Numerical results of the 3D FE simulation. Simulated distribution of the magnetic field $\mathrm{H}$ as a function of $y$ axis at the sample center $(x=0, z=0)$. From the sensor position (see inset (a)) $Y 1=-6.5$ $\mathrm{mm}$ and $\mathrm{Y} 2=-3.5 \mathrm{~mm}$, a linear extrapolation (shown graphically by the red line) towards the sample surface $y=-0.5 \mathrm{~mm}$ enables to determine the magnetic field at the surface of the sample. 15

Figure 6: Numerical results of the 3D FE simulation. (a) Magnetic induction B (T) and (b) Magnetic field $\mathrm{H}(\mathrm{A} / \mathrm{m})$ distribution in the mini SST (yoke and sample) 16

Figure 7: Experimental measurement of the electrical conductivity in different locations of a CP using the proposed four point method based approach. The inset above illustrates the four different areas of sampling (A, B, C and D).

Figure 8: Comparison of $\mathrm{CP} B(\mathrm{H})$ curves measured with the mini SST and $\mathrm{CP} B(\mathrm{H})$ reference curves obtained from the ring core measurement at $5 \mathrm{~Hz}$. The inset illustrates the sampling areas. 18 
Figures

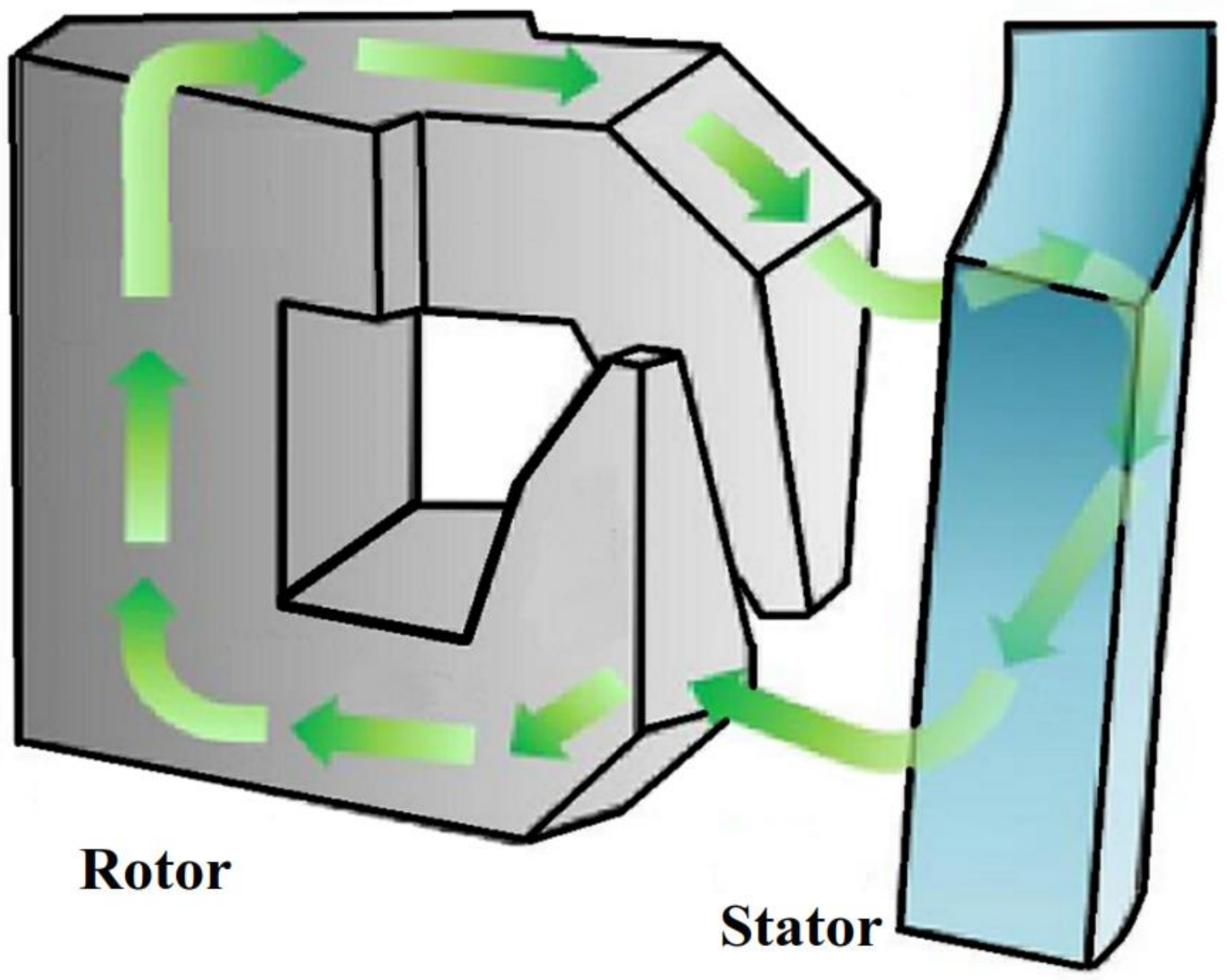

Figure 1: Main Magnetic flux path through 1/6th of the CP 


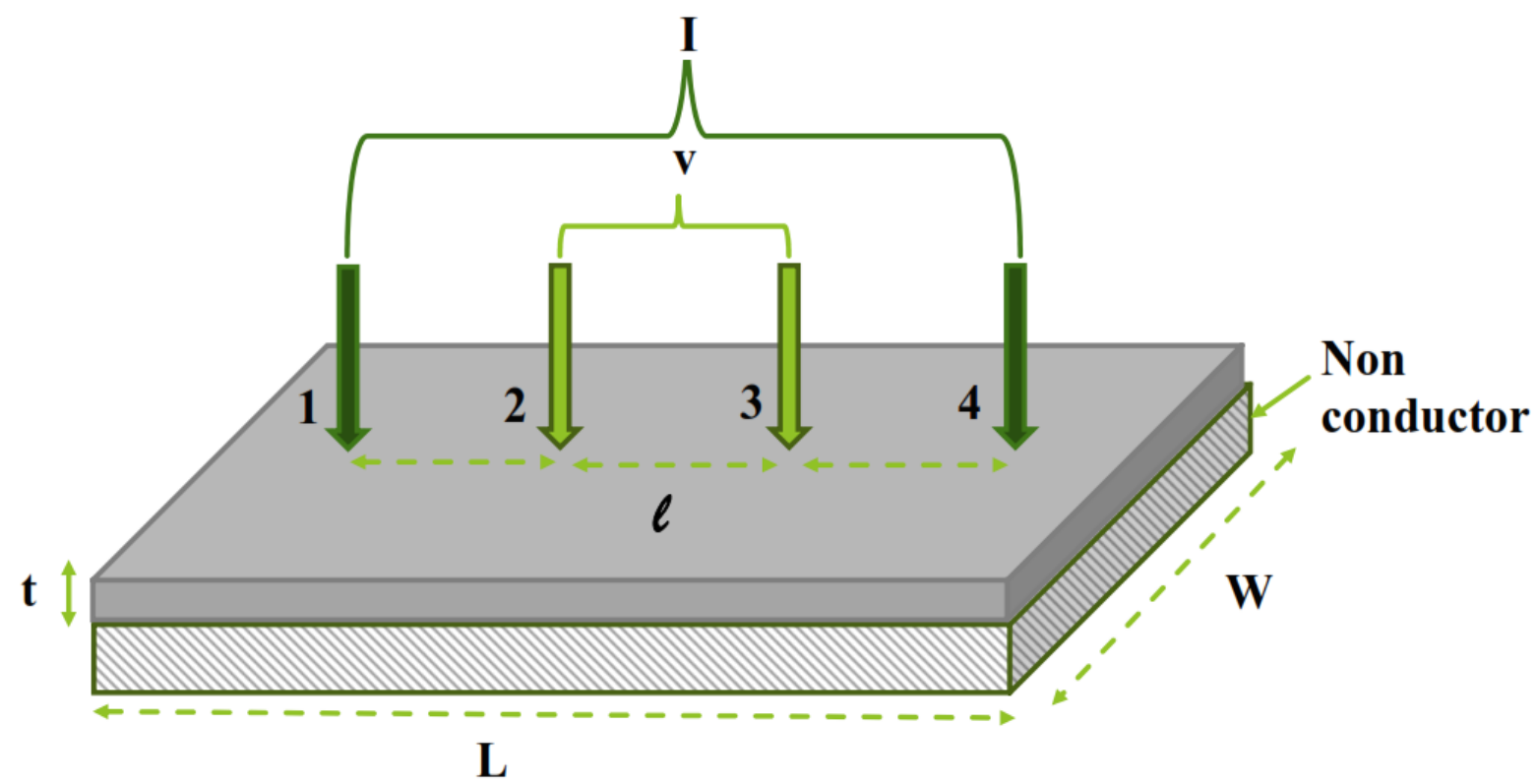

Figure 2: Four point method 


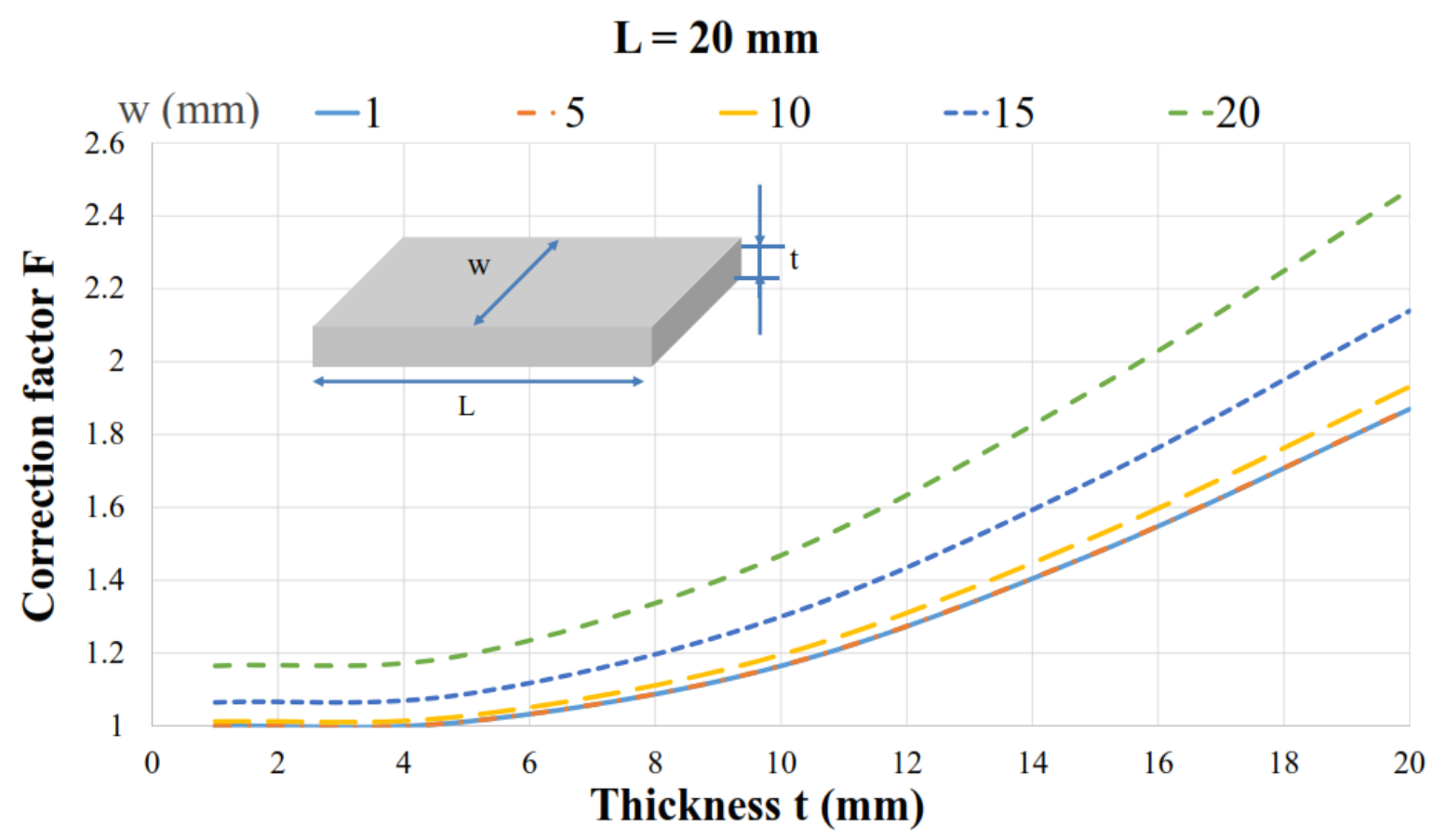

(a)

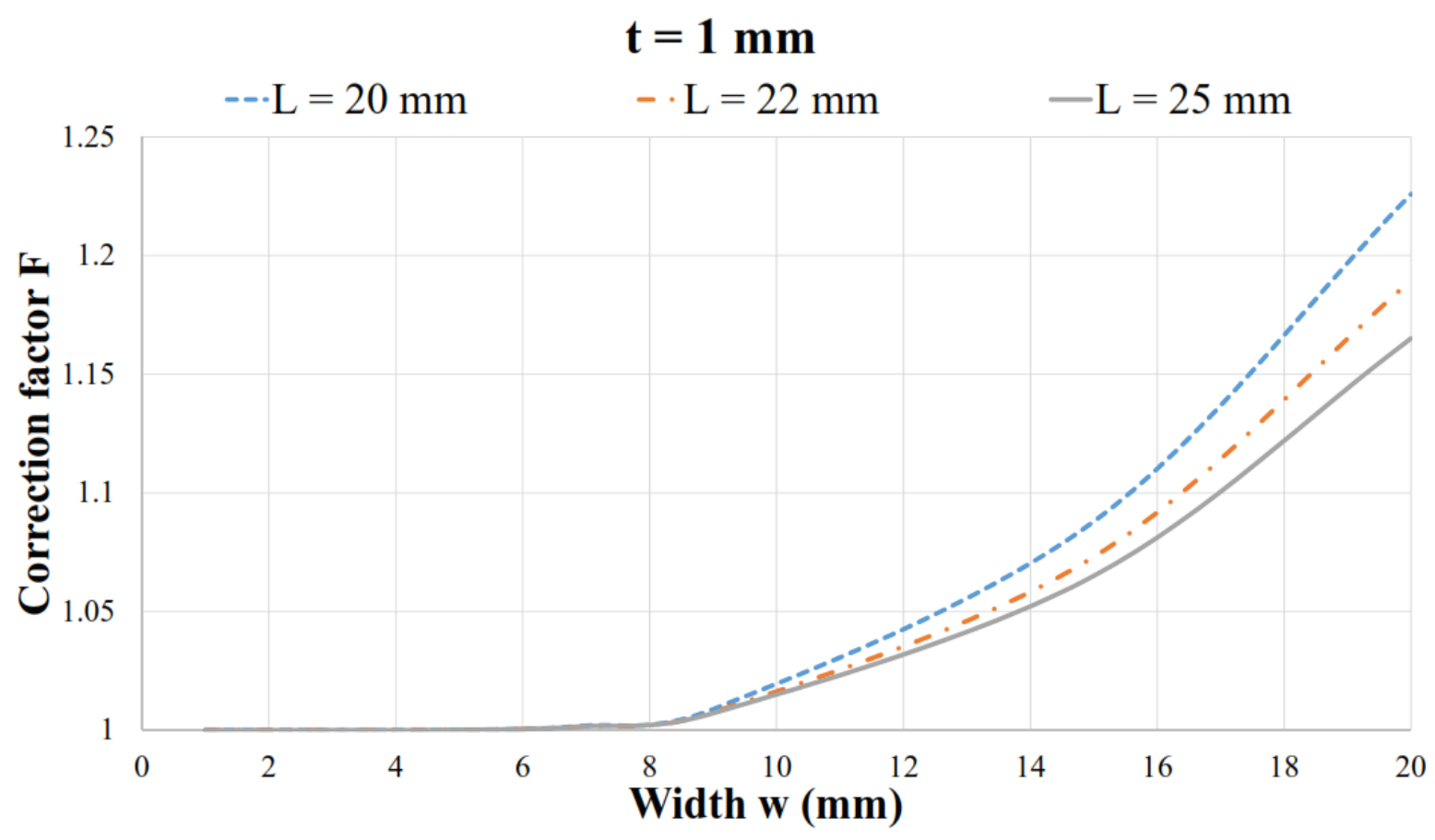

(b)

Figure 3: Abacus of the geometrical correction factor numericaly calculated according to equation (1) for different sample dimensions with a parallepipedic shape. (a) The correction 
factor vs the sample thickness for five different widths at fixed length ( $\mathrm{L}=20 \mathrm{~mm})$. (b) The correction factor vs the sample width for three different lengths at fixed thichness $(\mathrm{t}=1 \mathrm{~mm})$. 




(a)

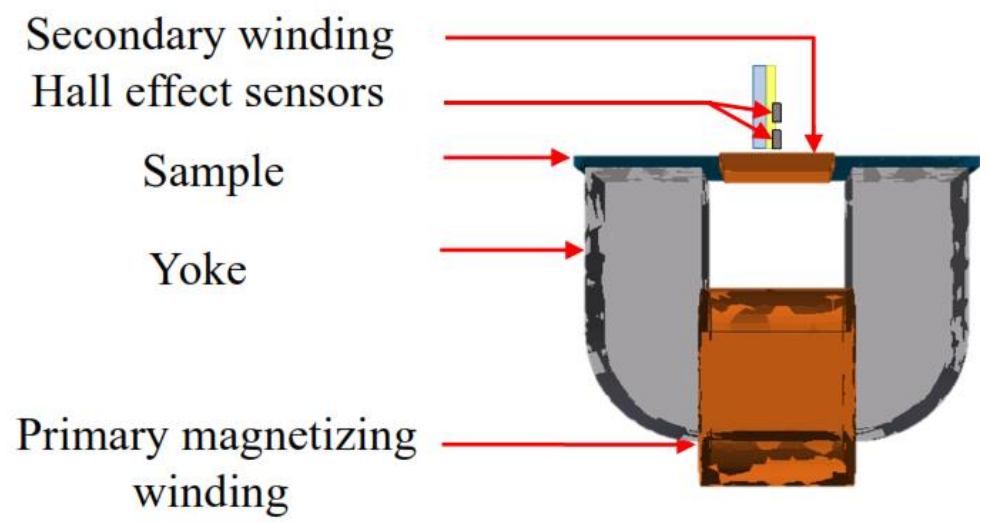

(b)

Figure 4: Photography (a) and schematic view (b) of the mini SST. 


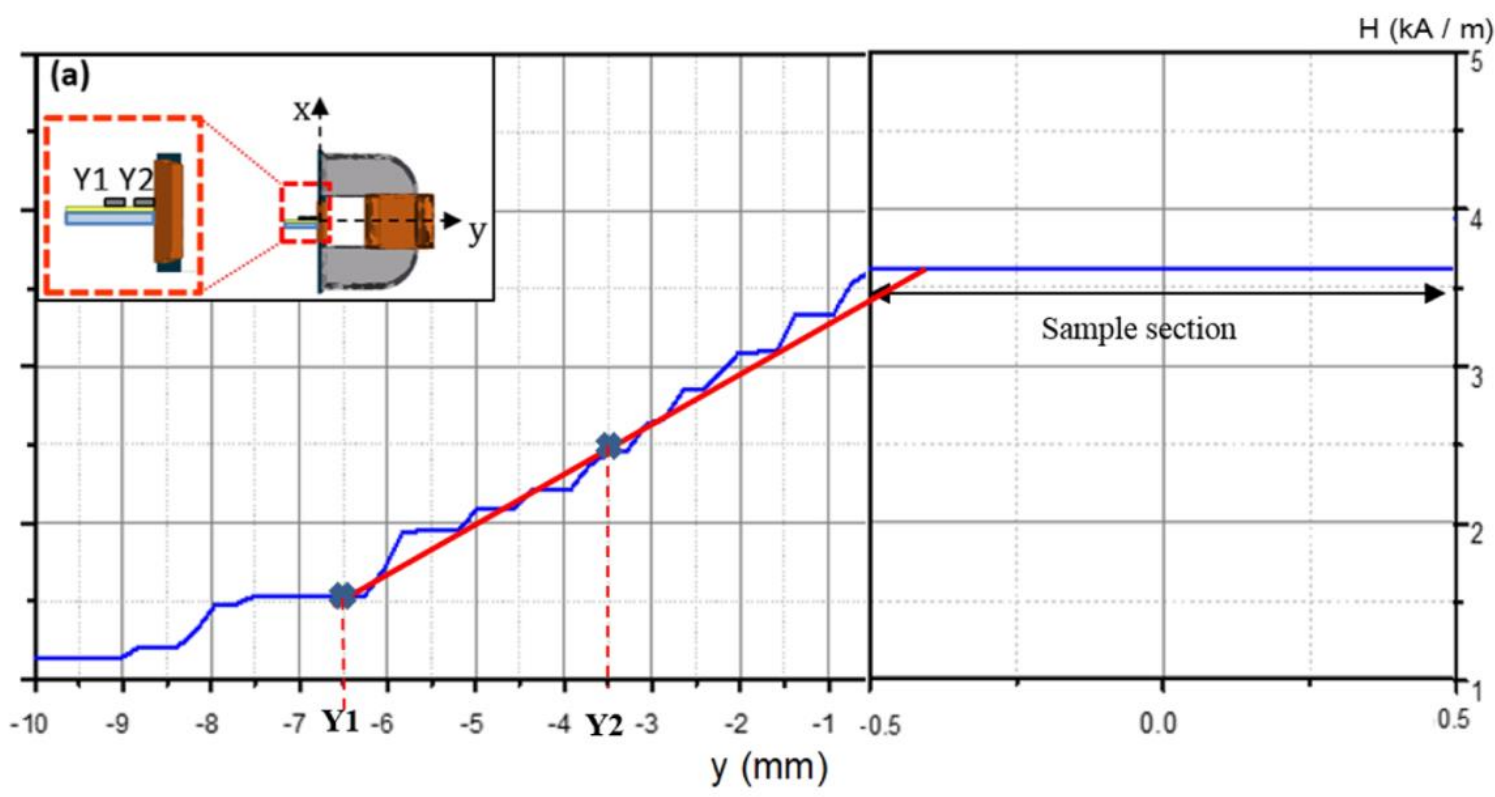

Figure 5: Numerical results of the 3D FE simulation. Simulated distribution of the magnetic field $\mathrm{H}$ as a function of $\mathrm{y}$ axis at the sample center $(\mathrm{x}=0, \mathrm{z}=0)$. From the sensor position (see inset (a)) $\mathrm{Y} 1=-6.5 \mathrm{~mm}$ and $\mathrm{Y} 2=-3.5 \mathrm{~mm}$, a linear extrapolation (shown graphically by the red line) towards the sample surface $y=-0.5 \mathrm{~mm}$ enables to determine the magnetic field at the surface of the sample. 


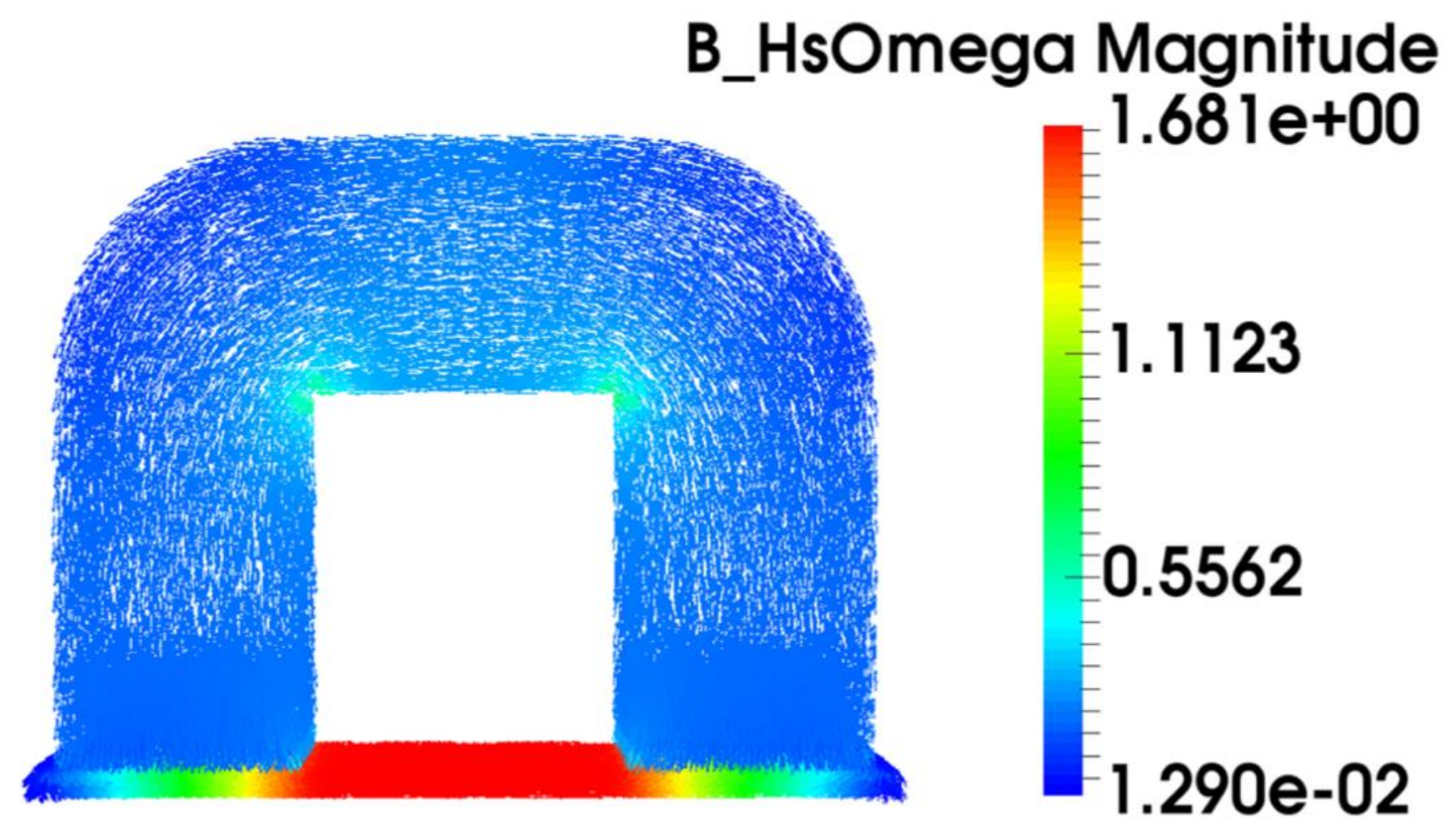

(a)

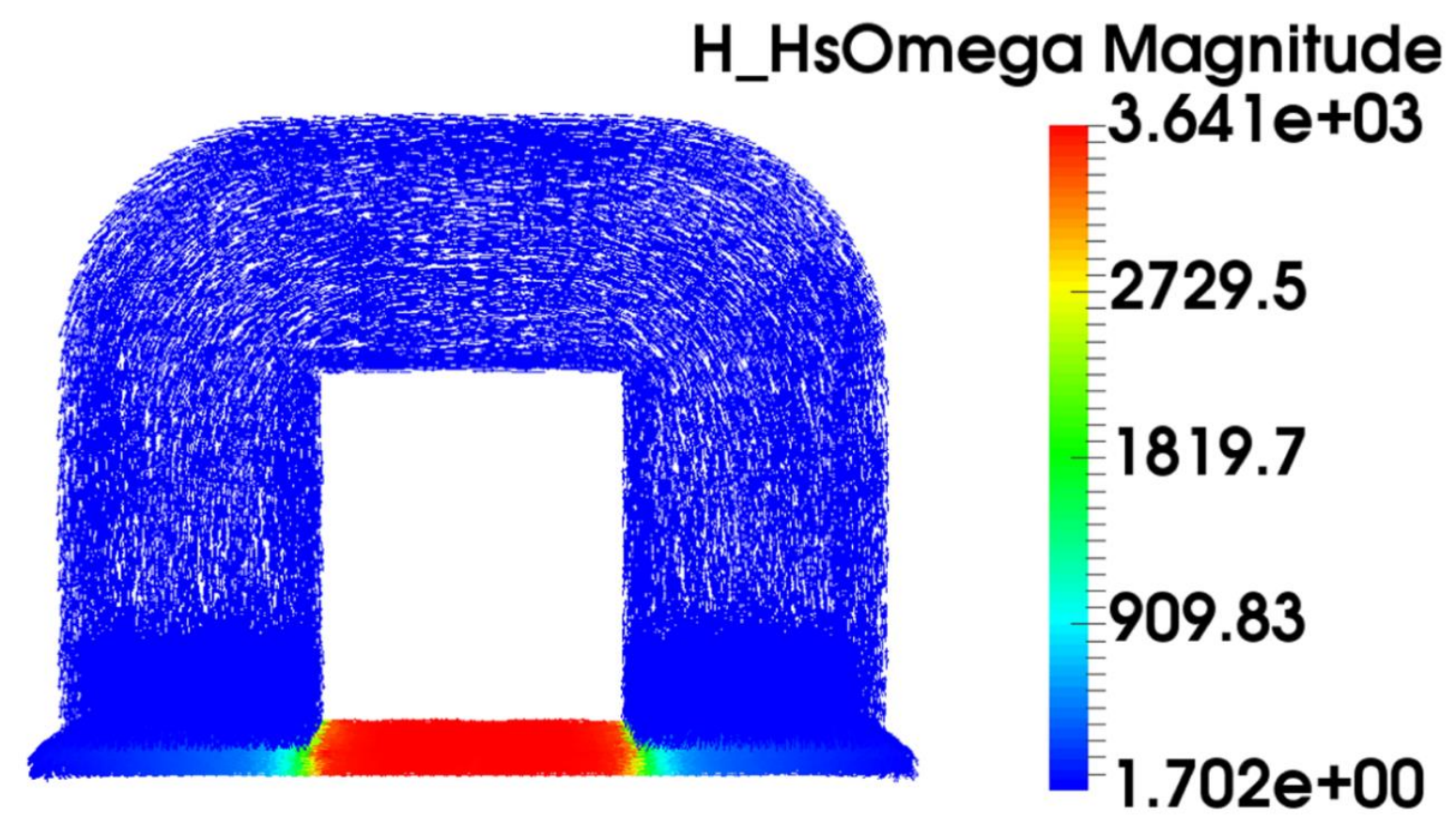

(b)

Figure 6: Numerical results of the 3D FE simulation. (a) Magnetic induction B (T) and (b) Magnetic field $\mathrm{H}(\mathrm{A} / \mathrm{m})$ distribution in the mini SST (yoke and sample) 




Figure 7: Experimental measurement of the electrical conductivity in different locations of a $\mathrm{CP}$ using the proposed four point method based approach. The inset above illustrates the four different areas of sampling (A, B, C and D). 


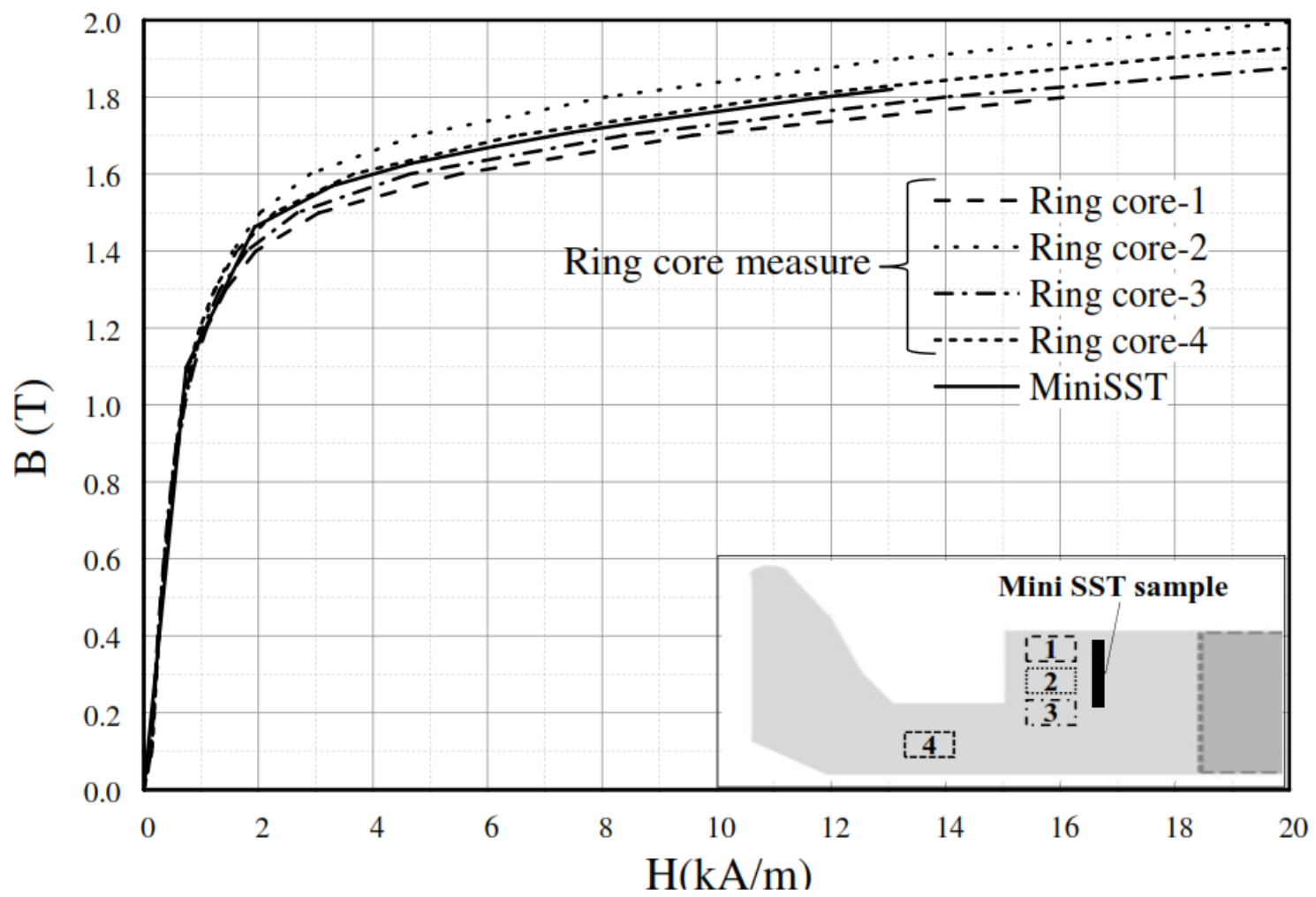

Figure 8: Comparison of $\mathrm{CP} \mathrm{B}(\mathrm{H})$ curves measured with the mini SST and $\mathrm{CP} B(\mathrm{H})$ reference curves obtained from the ring core measurement at $5 \mathrm{~Hz}$. The inset illustrates the sampling areas. 